\title{
Genetic variability in banana diploids and nonparametric statistics of fragments associated with natural fruit finger drop
}

\author{
M.A. Rodrigues ${ }^{1}$, E.P. Amorim ${ }^{2}$, C.F. Ferreira ${ }^{2}$, C.A.S. Ledo ${ }^{2}$ and \\ J.R.F. Santana ${ }^{1}$ \\ ${ }^{1}$ Universidade Estadual de Feira de Santana, Feira de Santana, BA, Brasil \\ ${ }^{2}$ Embrapa Mandioca e Fruticultura, Cruz das Almas, BA, Brasil \\ Corresponding authors: C.F. Ferreira / E.P. Amorim \\ E-mail: claudia.ferreira@embrapa.br / edson.amorim@embrapa.br
}

Genet. Mol. Res. 16 (3): gmr16039554

Received November 24, 2016

Accepted February 15, 2017

Published July 28, 2017

DOI http://dx.doi.org/10.4238/gmr16039554

Copyright (C) 2017 The Authors. This is an open-access article distributed under the terms of the Creative Commons Attribution ShareAlike (CC BY-SA) 4.0 License.

\begin{abstract}
Natural fruit finger drop in bananas is one of the major concerns of producers as well as consumers. The aim of this study was to estimate the genetic diversity among 15 diploid bananas with different levels of resistance to finger drop (RFD) using SSR and ISSR (inter-simple sequence repeat) markers, and assess the possibility of association of bands with RFD variables ( 11 and v2) via nonparametric methodologies. Molecular genetic analysis revealed that the dendrogram generated by SSR markers used as co-dominant markers better discriminated the genotypes as to genome constitution, genealogy, and RFD. Although nonparametric tests are limited in terms of inferences, they are very useful when data do not follow normal distribution, such as the case in our study. Bananas are parthenocarpic, which hinders obtainment of representative genetic linkage maps and linkage studies due to small number of segregating populations; a prerequisite for mapping and QTL studies. Therefore, non-conventional methodologies, such as nonparametric tests, become an attractive
\end{abstract}

Genetics and Molecular Research 16 (3): gmr16039554 
alternative to overcome this barrier. In our study, the nonparametric tests, Kruskal-Wallis and Spearman correlation, revealed negative and positive associations with RFD for 12 bands (7 from ISSR markers and 5 from SSR markers) with high positive and negative correlations. The results show potential for future sequencing of bands, obtaining sequence-characterized amplified region markers, validation, and subsequent possibility for application in marker-assisted selection in banana genetic breeding programs. This is the first report of the use of nonparametric statistics in attempt to evaluate the association between fruit finger drop and ISSR bands in Musa spp.

Key words: Musa spp; Microsatellites; ISSR; Nonparametric statistics

\section{INTRODUCTION}

Bananas are considered one of the most important fruits playing significant social and economic roles worldwide. Brazil is the fifth world producer, with 7.3 million tons produced in 2014, in 500,000 hectares (FAO - Food and Agriculture Organization, 2016). Among the many bottlenecks in banana marketing and causes of substantial post-harvest losses, natural fruit finger drop is one of the major complaints of consumers. This condition is a physiological disorder associated with maturation that, in bananas, is also associated with softening and weakening of the peel in the junction between the fruit and the bunch, called pedicel (Imsabai et al., 2006; Salazar and Serrano, 2013).

Bananas are sold in clusters ranging from 4 to 9 fruits. Therefore, the displacement of individual fruits in the pedicel area is one of the main causes of the decline in the market value and consumer acceptance, generating significant economic impact on producers. Bananas were developed through complex intra- and inter-specific crosses of two diploid species of the genus Musa: Musa acuminata Colla, with genome A, and Musa balbisiana Colla, with genome B. During domestication, crosses produced varying combinations of complete genomes of both parental species as follows: diploids (AA, $\mathrm{AB}$, and $\mathrm{BB}$ ); triploids (AAA, $\mathrm{AAB}$, and $\mathrm{ABB}$ ) and tetraploids (AAAA, AAAB, AABB, and ABBB) (Simmonds and Shepherd, 1955), where the A genome is responsible for palatability and taste and the $\mathrm{B}$ genome for robustness and disease resistance.

Susceptibility to fruit finger drop varies among cultivars and it was first reported in the triploid Cavendish (AAA) (Hicks, 1934) and banana tetraploids (Marriott, 1980). However, several studies suggest that besides ploidy level, the type of genome also influences susceptibility. Bananas that have the B genome are less prone to fruit dropping when compared to bananas with the A genome (Putra et al., 2010).

This indicates that the alleles of resistance to finger drop (RFD) may be associated with the Musa balbisiana species. Studies carried out by Pereira et al. (2004) confirm that the

diploid M. balbisiana (BB) and triploids with the $\mathrm{B}$ genome (ABB and $\mathrm{AAB}$ ) showed higher resistance to fruit drop when compared to diploids and triploids of M. acuminata (AA and AAA) and tetraploids of this same group.

Microsatellite markers have been widely used to assess the genetic diversity in diploid genotypes of Musa spp (Creste et al., 2003; Amorim et al., 2009). Microsatellites or simple sequence repeats (SSR) are co-dominant markers with motifs that can vary from 1 to

Genetics and Molecular Research 16 (3): gmr16039554 
6 nucleotides repeated in tandem within the genomes of prokaryote and eukaryote organisms. The flanking regions, which are usually highly conserved, are suitable for the development of site-specific primers (Iniguez-Luy et al., 2008).

ISSR markers (inter-simple sequence repeats), which amplify a DNA sequence defined by two inverted microsatellite regions, also have potential for genetic diversity studies in Musa (Racharak and Eiadthong, 2007; Lu et al., 2011). Such markers are dominant and highly reproducible with the advantage of generating large quantities of bands, being widely distributed throughout the genome.

One of the strategies to reduce the problem associated with fruit finger drop is the development of resistant cultivars from the selection of progenitors with good combining ability and resistance to this characteristic. In order to improve breeding programs, molecular markers have played a key role in indirect selection of genotypes with resistance to pests and diseases, by associating bands or alleles of interest via nonparametric methods (Mace et al., 2006; Mondal and Badigannavar, 2010; Singh et al., 2013). Although these methods are somewhat limited, with restricted inferences (Whitely and Ball, 2002; Cowan, 1992), they may be used when data do not follow normal distribution and have shown to be useful in association studies, especially for orphan crops that have very limited genomic resources including genetic maps with sufficient marker coverage, which are pre-requisites for a conventional mapping approach. In Musa spp this is even more important, since they are parthenocarpic, with very low seeds, and very few individuals can be obtained in segregating populations.

Different banana-breeding programs have produced tri- and tetraploid hybrids obtained from crosses between fertile triploid cultivars or tetraploid hybrids (female parent) and improved diploids (pollen donor) (Crouch et al., 1999; Amorim et al., 2016). Therefore, knowledge of the genetic variability of diploids available for genetic improvement is useful information when selecting parents for crosses between different genotypes (Amorim et al., 2009).

The aim of this study was to estimate the genetic variability among 15 banana diploids with different levels of fruit RFDusing SSR and ISSR markers and assess the possibility of association of fruit finger drop resistance with ISSR and SSR bands via nonparametric statistics.

\section{MATERIAL AND METHODS}

\section{Genetic material}

The 15 banana genotypes evaluated included cultivated, improved, and wild diploids and with different levels of RFD, belonging to the banana germplasm collection at Embrapa Mandioca e Fruticultura, Cruz das Almas, BA (Table 1).

\section{Fruit dropping scale and measurements}

RFD data were obtained by previous study carried out by Pereira et al. (2004). Values for RFD were the following: 1 for resistant $(\mathrm{R})$ genotypes $(>60 \mathrm{~N}), 2$ for moderately resistant (MR; 20-60 N), and 3 for susceptible genotypes $(<20 \mathrm{~N})($ Table 1$)$.

\section{Molecular markers}

Thirty SSR markers (Table 2) and 13 ISSR markers (Table 3) were used for the genetic

Genetics and Molecular Research 16 (3): gmr16039554 
diversity analysis of 15 banana genotypes with different patterns for RFD. Once the molecular and phenotypic data for RFD were available (Pereira et al., 2004), they were used to verify the presence or not of possible correlation with the variables for RFD, using nonparametric tests.

Table 1. Banana diploid genotypes indicating the genomic group (GG), genealogy, geographical origin, and resistance to finger drop (RFD) and variable 1 (V1) and variable 2 (V2).

\begin{tabular}{l|l|l|l|l}
\hline Name & GG & Genealogy & Origin & RFD \\
\hline BB França & BB & Wild diploid $^{1}$ & France & Resistant \\
\hline Butuhan & BB & Wild diploid $^{1}$ & Philippines & Resistant \\
\hline ID028003-01 & AA & Improved diploid $^{2}$ & Honduras & Resistant \\
\hline Khai Nai On & AA & Cultivated diploid & Thailand & Resistant \\
\hline Hibrido AB & AB & Improved diploid & Brazil & M resistant \\
\hline Ouro & AA & Cultivated diploid & Brazil & M resistant \\
\hline Tjau Lagada & AA & Cultivated diploid & Costa Rica & M resistant \\
\hline TH0301 & AA & Improved diploid & Brazil & M resistant \\
\hline Jary Buaya & AA & Cultivated diploid & Honduras & M resistant \\
\hline Jaran & AA & Improved diploid & Indonesia & M resistant \\
\hline Lidi & AA & Cultivated diploid & Costa Rica & Susceptible \\
\hline M53 & AA & Improved diploid & Equador & Susceptible \\
\hline Calcutta 4 & AA & Wild diploid & Jamaica & Susceptible \\
\hline ID013004-04 & AA & Improved diploid & Brazil & Susceptible \\
\hline ID017041-01 & AA & Improved diploid & Brazil & Susceptible \\
\hline
\end{tabular}

${ }^{1}$ Genotype that bears fruit with seeds; ${ }^{2}$ genotype obtained by crossing wild diploids; ${ }^{3}$ genotypes that bears seedless fruits by parthenocarpy. M resistant = moderately resistant. RFD based on the study of Pereira et al. (2004).

\section{DNA extraction and PCR}

Genomic DNA was extracted from young leaves from 15 banana genotypes using the CTAB method (Doyle and Doyle, 1990) (Table 1). Amplification reactions were performed in a final volume of $15 \mu \mathrm{L}$ containing the following reagents: $50 \mathrm{mM} \mathrm{KCl}, 10 \mathrm{mM}$ Tris-HCl, $\mathrm{pH}$ 8.3, $2.5 \mathrm{mM} \mathrm{MgCl}, 100 \mu \mathrm{M}$ of each one $\mathrm{f} \mathrm{dNTPs} \mathrm{(dATP,} \mathrm{dTTP,} \mathrm{dGTP,} \mathrm{and} \mathrm{dCTP,} \mathrm{dCTP),} 0.2$ $\mathrm{mM}$ of each primer, $1 \mathrm{U}$ Taq polymerase (Pharmacia Biotech, USA) and 20 ng genomic DNA.

Thirty microsatellite primers: four from the Ma series (Crouch et al., 1998), five from the AGMI series developed by Lagoda et al. (1998), three from the MaOCEN series (Creste et al., 2006), ten from the CNPMF series (Amorim et al., 2012), and eight from the MASR series (Dr. Ana Ciampi - Embrapa CENARGEN) (Table 2), and thirteen ISSR markers (Table $3)$, were used for genetic molecular characterization.

Amplifications were performed on the Applied Biosystems thermocycler, using specific annealing temperature (Ta) for each primer. Amplification conditions included one cycle of denaturation for $3 \mathrm{~min}$ at $94^{\circ} \mathrm{C}$ followed by 30 cycles of denaturation for $40 \mathrm{~s}$ at $94^{\circ} \mathrm{C}$, $40 \mathrm{~s}$ Ta specific for each primer, 1 min extension at $72^{\circ} \mathrm{C}$, ending with a final extension of 4 min at $72^{\circ} \mathrm{C}$ and $10^{\circ} \mathrm{C} \infty$. Fragments were separated on 3 and $2.5 \%$ ultrapure- 1000 agarose gel (Invitrogen, Carlsbad, CA, USA) for the SSR and ISSR markers, respectively, under standard conditions, stained with ethidium bromide, visualized under UV light and photo-documented using the UVITEC equipment.

\section{Data analysis}

\section{Genetic diversity analysis}

For the genetic diversity analysis, three dendrograms were constructed: 1) ISSR 
markers, 2) a combined dendrogram using ISSR and SSR markers as dominant markers and 3 ) using SSR markers as co-dominant markers. Data from ISSR markers were computed as (0) absence and (1) presence of the band, SSR markers as co-dominant markers were computed as base pairs of fragments with the estimated size in base pairs for each allele obtained by the method of reverse mobility based on regression of products of known size of the molecular marker (50 bp) (Fermentas, USA) and for the dendrogram constructed with the combined data, both ISSR and SSR markers were scored as (0) and (1).

The genetic distance matrix was calculated using the Jaccard coefficient for the ISSR and combined ISSR and SSR markers approach and the Nei and Li (1979) coefficient for the SSRs as co-dominant markers. Clusters were generated by the UPGMA (unweighed pairgroup method of arithmetic average) method and dendrograms constructed using the Statistica software (Statistica for Windows, 2002). Validation of the clusters was determined by the cophenetic correlation coefficient (CCC) (Sokal and Rohlf, 1962) using the GENES software (Cruz, 2006) and the cut-off established according to criteria suggested by Mingoti (2005).

\section{Nonparametric methodology}

Nonparametric tests, although somewhat statistically limited, are used when the data do not follow normal distribution (Cowan, 1992; Whitely and Ball, 2002), such as the case in our study, and therefore were chosen to investigate any possible correlation between bands and phenotypic variation for finger drop in banana fruits since both phenotypic and genotypic data were available.

The electrophoretic profile of a total of 208 bands (ISSR - 139 and SSR - 69 bands) computed as (1) and (0) along with the results of analysis for the finger drop variables: v1 $=$ force necessary to release the fruit from the pedicel using a mechanical fruit detacher developed by Cerqueira et al. (2000): resistant genotypes ( $>60 \mathrm{~N})$, MR genotypes (20-60 N), and resistant genotypes $(<20 \mathrm{~N})$; v2: scale proposed by Pereira et al. (2004) where 1 = resistant genotypes, 2 = MR genotypes, and 3 = susceptible genotypes, were submitted to the Spearman correlation and Kruskal- Wallis (Kruskal, 1964)- nonparametric tests. The SAS software (SAS Institute Inc., 2002-2004) was used with the PROC CORR Spearman and PROC NPAR1WAY ANOVA and exact Wilcoxon commands to verify the presence of any correlation between band and variables.

The RFD variable refers to the average of the RFD of the fruit expressed in Newtons $(\mathrm{N})$, meaning the strength applied to the finger drop measurer (equipment) necessary to separate the fruit from the pedicel. Therefore, the higher the number in Newtons, the greater the force necessary to separate the fruit from the pedicel and more resistant is the genotype to finger drop. In contrast, lower numbers are attributed to genotypes more susceptible to finger drop. The scale, which varies from 1 to 3 , refers to levels of variable RFD, where more resistant genotypes are given number 1, and more susceptible genotypes, 3 (Pereira et al., 2004).

\section{RESULTS AND DISCUSSION}

\section{Genetic diversity analysis using SSR and ISSR markers}

Microsatellites and ISSR markers are widely used in Musa spp genetic diversity studies (Hippolyte et al., 2012; Lamare and Rao, 2015; Silva et al., 2015). In our study, SSR

Genetics and Molecular Research 16 (3): gmr16039554 
and ISSR markers were used to evaluate the genetic diversity of 15 banana diploids with different levels of finger drop resistance.

The electrophoretic profile with microsatellite marker SSR-MASR185 and ISSR marker ISSR-55 is shown in Figure 1A and B.
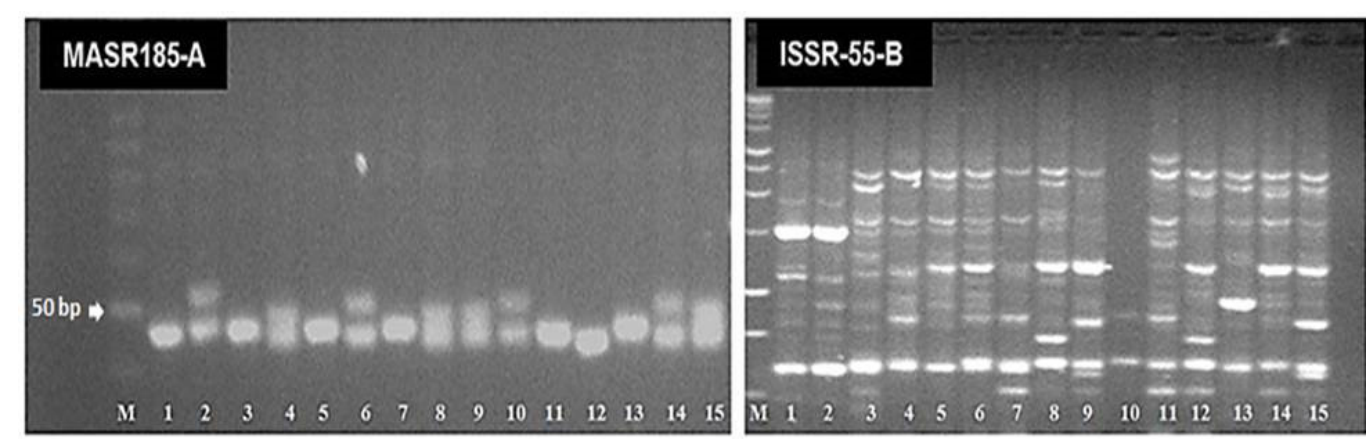

Figure 1. Electrophoretic profile on 3 and 2.5\% agarose gels for marker SSR-MASR185 (A) and ISSR-55 (B), respectively, of 15 banana genotypes used in the study of genetic variability and resistance to finger drop (RFD). Lane 1 = BB-França; lanes 2 = Butuhan; lanes $3=\mathrm{ID} 028003-01$; lanes $4=$ Khai Nai On; lanes $5=$ Hibrido AB; lanes $6=$ Ouro; lanes $7=\mathrm{Tjau}$ Lagada; lanes $8=\mathrm{TH} 0301$; lanes $9=$ Jary Buaya; lanes $10=\mathrm{Jaran}$; lanes $11=\mathrm{Lidi}$; lanes $12=\mathrm{M} 53$; lanes $13=$ Calcutta-4; lanes $14=$ ID013004-04; lanes $15=$ ID017041-01. Lane $M=$ molecular marker - $50 \mathrm{bp}$ (A) and 1-kb ladder (Invitrogen) (B).

The genetic diversity analysis was evaluated by comparing three dendrograms: i) using 13 ISSR markers, ii) a combined dendrogram with 13 ISSR and 30 SSR markers scored as dominant markers, and iii) 30 SSR markers scored as co-dominant markers (bp of fragments).

From the 30 microsatellite primers assessed, 139 alleles were obtained, with an average of 4.7 alleles per locus. The smallest number of alleles was for primers AGMI 103/104, MASR 148, MASR 154, MASR 153, and CNPMF 3 (2 alleles) and the highest for primer Ma 3/103 (11 alleles) (Table 2). Considering only the results for banana diploids, the average of alleles per locus in our study is in agreement with those found by Amorim et al. (2008) (7.53 alleles) and Amorim et al. (2009) (7.51 alleles).

Ma series (Crouch et al., 1998), AGMI series (Lagoda et al., 1998), MaOCEN (Creste et al., 2006), CNPMF (Amorim et al., 2012), and MASR (Dr. Ana Ciampi - Embrapa CENARGEN).

The polymorphism information content (PIC), which provides an estimate of the discriminatory power of the marker, ranged from 0.16 to 0.86 for primers AGMI 103/104 and Ma 3/103, respectively, averaging 0.52 (Table 3). According to Botstein et al. (1980), markers with PIC values greater than 0.5 are considered highly informative, therefore, primer Ma 3/103 was considered highly polymorphic.

Three dendrograms were constructed: i) using 13 ISSR markers (Figure 2), ii) 30 SSR and 13 ISSR markers scored as (0) and (1) in a combined analysis (Figure 3), and iii) 30 SSR markers scored as co-dominant markers (bp of fragments) (Figure 4). In average, for all three dendrograms, the cophenetic correlation coefficient (CCC), which measures the consistency of the clusters was 0.94, considered adequate for these studies (Vaz Patto et al., 2004).

Genetics and Molecular Research 16 (3): gmr16039554 
Table 2. Microsatellites used in genetic diversity and nonparametric test analysis: sequence locus, number of alleles, and polymorphism information content (PIC).

\begin{tabular}{|c|c|c|c|}
\hline SSR locus name & Sequence $\left(5^{\prime}-3^{\prime}\right)$ & Number of alleles & PIC \\
\hline AGMI 105/108 & $\begin{array}{l}\text { F: tcccaacccctgcaaccact } \\
\text { R: atgacctgtcgaacatccttt }\end{array}$ & 3 & 0.46 \\
\hline AGMI 127/128 & $\begin{array}{l}\text { F: aagttaggrcaagatagtgggatt } \\
\text { R: cttttgcaccagttgttagg }\end{array}$ & 4 & 0.33 \\
\hline AGMI 129/130 & $\begin{array}{l}\text { F: ggaggcccaacataggaagaggaat } \\
\text { R: cataaacgacagtagaaatagcaac }\end{array}$ & 6 & 0.61 \\
\hline AGMI 103/104 & $\begin{array}{l}\text { F: acagaatcgctaaccetaatcctca } \\
\text { R: ccctttgcgtgccectaa }\end{array}$ & 2 & 0.16 \\
\hline AGMI 187/188 & $\begin{array}{l}\text { F: gcaactttggcagcatttt } \\
\text { R: tgatggactcatgtgtacctactat }\end{array}$ & 3 & 0.39 \\
\hline CNPMF 10 & $\begin{array}{l}\text { F: cacatcacacgctctgettc } \\
\text { R: ttttcggctgatccaattc }\end{array}$ & 3 & 0.48 \\
\hline CNPMF 2 & $\begin{array}{l}\text { F: tgatctcgacgctgcac } \\
\text { R: tgacagggcttccacttacag }\end{array}$ & 3 & 0.23 \\
\hline CNPMF 63 & $\begin{array}{l}\text { F: ggtgggcaacctgtaatctg } \\
\text { R: caccatttgggttttccaac }\end{array}$ & 5 & 0.73 \\
\hline CNPMF 14 & $\begin{array}{l}\text { F: catcgaggatgcacatcaag } \\
\text { R: ccaaaagagccacgattcag }\end{array}$ & 7 & 0.59 \\
\hline CNPMF 37 & $\begin{array}{l}\text { F: gagccgtggctgtcactaag } \\
\text { R: tatactctcgatcaccgggc }\end{array}$ & 8 & 0.77 \\
\hline CNPMF 60 & $\begin{array}{l}\text { F: tgaaatctgaaccetggtgg } \\
\text { R: acgcacacacacacacaatg }\end{array}$ & 7 & 0.75 \\
\hline CNPMF 20 & $\begin{array}{l}\text { F: cctcgcacatcaacccttac } \\
\text { R: catgatcaccatttcetccc }\end{array}$ & 6 & 0.51 \\
\hline CNPMF 19 & $\begin{array}{l}\text { F: gtgttcgagagctttcagcc } \\
\text { R: agaacaatcaagccagcagc }\end{array}$ & 4 & 0.63 \\
\hline CNPMF 32 & $\begin{array}{l}\text { F: aggettcgaccacaaactcc } \\
\text { R: agcgttctcgttccaatcac }\end{array}$ & 4 & 0.53 \\
\hline CNPMF 3 & $\begin{array}{l}\text { F: gggccaaccacatgatctac } \\
\text { R: actcgagcacaaatggaacc }\end{array}$ & 2 & 0.24 \\
\hline Ma $1 / 17$ & $\begin{array}{l}\text { F: aggcggggaatcggtaga } \\
\text { R: ggcgggagacagatggagt }\end{array}$ & 7 & 0.73 \\
\hline Ma 3/103 & $\begin{array}{l}\text { F: tcgcctctctttagctctg } \\
\text { R: tgttggaggatctgagattg }\end{array}$ & 11 & 0.86 \\
\hline Ma $1 / 24$ & $\begin{array}{l}\text { F: gagcccattaagctgaaca } \\
\text { R: ccgacagtcaacatacaataca }\end{array}$ & 6 & 0.65 \\
\hline Ma $1 / 27$ & $\begin{array}{l}\text { F: tgaatcccaagtttggtcaag } \\
\text { R: caaaacactgtccccatctc }\end{array}$ & 6 & 0.75 \\
\hline MaOCEN 3 & $\begin{array}{l}\text { F: ggaggaaatggaggtcaaca } \\
\text { R: ttcgggataggaggaggag }\end{array}$ & 3 & 0.35 \\
\hline MaOCEN 1 & $\begin{array}{l}\text { F: tctcaggaagggcaacaatc } \\
\text { R: ggaccaaagggaaagaaacc }\end{array}$ & 6 & 0.74 \\
\hline MaOCEN 10 & $\begin{array}{l}\text { F: ggaagaaagaagtggagaatgaa } \\
\text { R: tgaaatggataaggcagaagaa }\end{array}$ & 3 & 0.29 \\
\hline MASR 189 & $\begin{array}{l}\text { F: gatggttcgtccgtcagatt } \\
\text { R: cacagtcaccaaatccatcg }\end{array}$ & 7 & 0.78 \\
\hline MASR 166 & $\begin{array}{l}\text { F: cgagtccgaagtcgcttcta } \\
\text { R: ttgagettgtgectcctttt }\end{array}$ & 4 & 0.67 \\
\hline MASR185 & $\begin{array}{l}\text { F: gacactgctccacaaacect } \\
\text { R: gcttcttcgggtgtctgttc }\end{array}$ & 5 & 0.69 \\
\hline MASR 148 & $\begin{array}{l}\text { F: gcaagtgtggcaactgagaa } \\
\text { R: cagcctgcccgaattatta }\end{array}$ & 2 & 0.37 \\
\hline MASR 165 & $\begin{array}{l}\text { F: ggttggegtacgtgaagagt } \\
\text { R: cgctgttgccaacgtagata }\end{array}$ & 4 & 0.49 \\
\hline MASR 154 & $\begin{array}{l}\text { F: gagaggatcgaggaaaaggg } \\
\text { R: acggtgctgaaatatccagg }\end{array}$ & 2 & 0.20 \\
\hline MASR 153 & $\begin{array}{l}\text { F: ccgcccatcctcgattacat } \\
\text { R: gaataaaccatacaccgaggtaaa }\end{array}$ & 2 & 0.36 \\
\hline MASR 149 & $\begin{array}{l}\text { F: tcgtcaggtctgtatgcgag } \\
\text { R: ctgcaagaggacatcaaacaag }\end{array}$ & 4 & 0.39 \\
\hline Total & & 139 & - \\
\hline Average & & 4.7 & 0.52 \\
\hline
\end{tabular}

Genetics and Molecular Research 16 (3): gmr16039554 
Table 3. Thirteen ISSR primers used in genetic diversity and nonparametric test analysis: primer name, sequence, and total number of bands.

\begin{tabular}{l|l}
\hline Primer name & Sequence (5'-3') \\
\hline ISSR2-DiCA3'G & CACACACACACACACAG \\
\hline ISSR11-DiGA3'C & GAGAGAGAGAGAGAGAC \\
\hline ISSR12 -DiGA3'RC & GAGAGAGAGAGAGAGARC \\
\hline ISSR34-TriCAG3'RC & CAGCAGCAGCAGCAGRC \\
\hline ISSR45-TriTGT3'YC & TGTTGTTGTTGTTGTYC \\
\hline ISSR46-TriTGT5'CR & CRTGTTGTTGTTGTTGT \\
\hline ISSR 50-TriAAG 3'RC & AAGAAGAAGAAGAAGRC \\
\hline ISSR-55-TriACA 3'RC & ACAACAACAACAACARC \\
\hline ISSR56-TriACT 3'RC & ACTACTACTACTACTRC \\
\hline ISSR71-TriTCT 3'RC & TCTTCTTCTTCTTCTRC \\
\hline ISSR72-TriTCC 3'RC & TCCTCCTCCTCCTCCRC \\
\hline ISSR85-TriCCG 3'RC & CCGCCGCCGCCGCCGRC \\
\hline ISSR88-TriCGC 3'RC & CGCCGCCGCCGCCGCRC \\
\hline
\end{tabular}

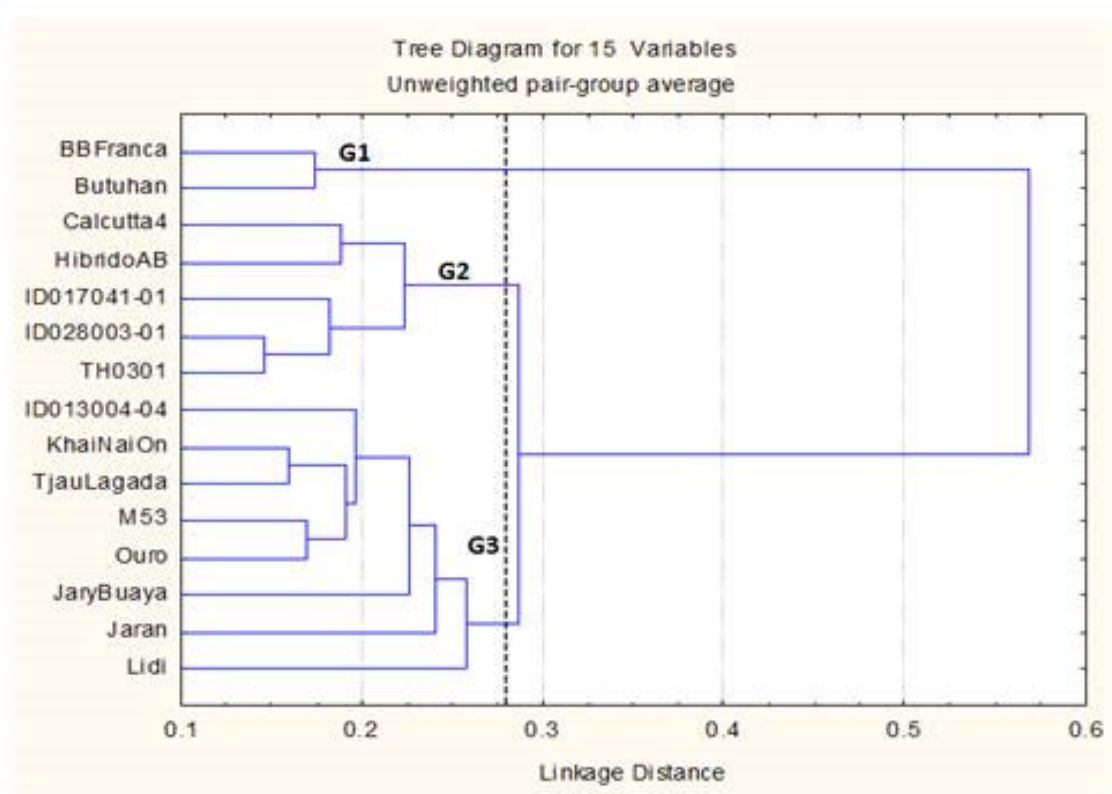

Figure 2. Dendrogram generated with 15 banana genotypes with different patterns of fruit drop resistance using 139 bands from 13 ISSR markers: (0) absence and (1) as presence of band. The distance matrix was calculated using the Jaccard coefficient index and clusters formed by the UPGMA method using the Statisitica software (Statistica for Windows, 2002). The cut-off was based on the criteria proposed by Mingoti (2005).

In general, the three dendrograms were not able to separate the genotypes according to their finger drop resistance patterns, except for groups G1 (Figures 2 and 3), where both genotypes are resistant to finger drop, and G1 (Figure 4), with both genotypes susceptible to finger drop, improved diploids, ID017041-01, and ID013004-04, and G3 comprised of R and MR genotypes (Figure 4).

The dissimilarity distances for the dendrogram generated by 139 ISSR markers (Figure 2), varied from 0.15 to $0.61 \%$, with the most similar genotypes being TH0301 and ID0280031 and the most dissimilar, BB França and Jaran, and Jary Buaya and Butuhan. This dendrogram 
separated the gentoypes into three major groups: G1: BB França and Butuhan (BB); G2: ID017041-01(AA), ID028003-01 (AA), TH0301 (AA), Calcutta 4 (AA) and Híbrido AB, and G3: ID013004-04 (AA), Khai Nai On (AA), Tjau Lagada (AA), M53 (AA), Ouro (AA), Jary Buaya (AA), Jaran (AA), and Lidi (AA). Although groups G1 and G3 separated the genotypes according to their genomes, BB and AA, respectively, only G1 separated them according to genomic constitution and RFD: BB França and Butuhan.

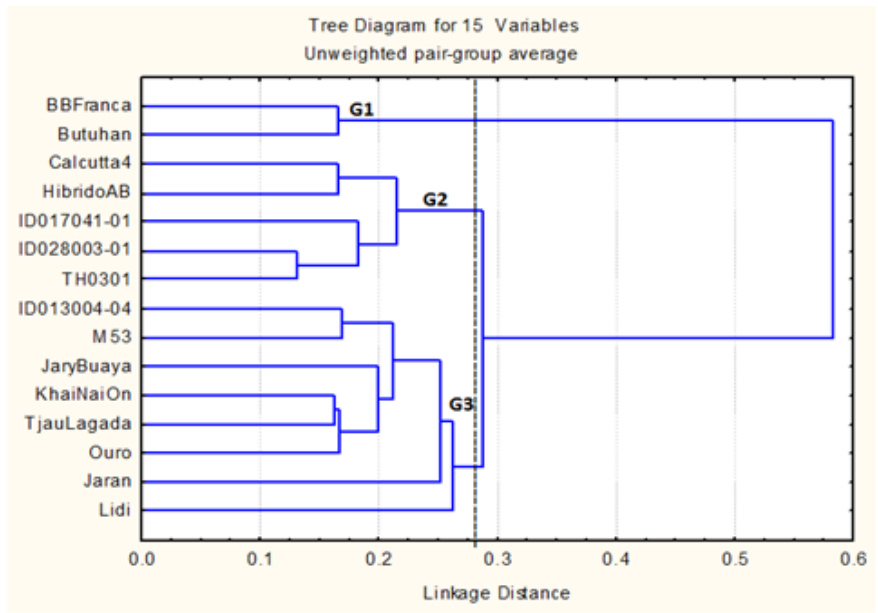

Figure 3. Dendrogram generated with 15 banana genotypes with different patterns of fruit drop resistance using 208 bands from 13 ISSR markers (139) and 30 SSR markers (69) scored as dominant markers: (0) absence and (1) as presence of band. The distance matrix was calculated using the Jaccard coefficient index and clusters formed by the UPGMA method using the Statistica software (Statistica for Windows, 2002). The cut-off was based on the criteria proposed by Mingoti (2005).

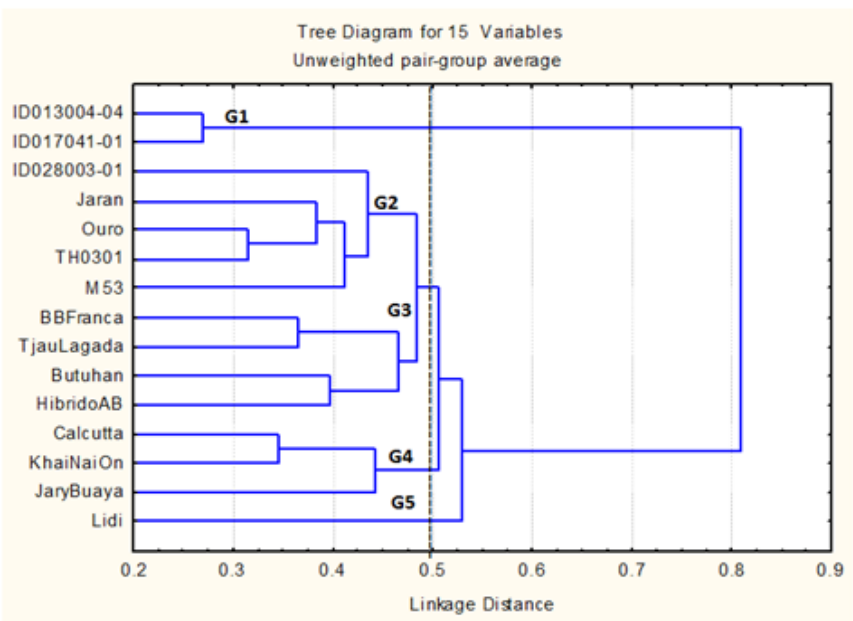

Figure 4. Dendrogram generated with 15 banana genotypes with different levels of resistance to finger drop (RFD) using 139 SSR polymorphic bands with scores based on bp of fragments. The distance matrix was calculated using the Nei and $\mathrm{Li}$ (1979) coefficient and clusters formed by the UPGMA method using the Statistica software (Statistica for Windows, 2002). The cut-off was based on the criteria proposed by Mingoti (2005).

Genetics and Molecular Research 16 (3): gmr16039554 
Group G3 presented the largest number of moderately resistant genotypes: Jaran (AA), Jary Buaya (AA), Ouro (AA), Tjau Lagada (AA), - and susceptible: Lidi (AA), ID01300404 (AA), M53 (AA), also grouping a genotype considered resistant, Khai Nai On (AA). ID013004-04 and Calcutta-4 in this same group are interesting, because Calcutta-4 was used as grandmother in the cross with ID013004-04. ID028003-01 (AA) and Calcutta-4 also in the same group can be explained because Calcutta-4 is one of the parents of ID280031.

The Lidi (AA), susceptible genotype, although clustered in group 3, remained separated from the other genotypes. This is justified once this genotype is known to present translocation and inversion events, which makes it very distinct among Musa genotypes (Shepherd, 1999).

The dendrogram generated by ISSR markers only presented similar results obtained for the combined analysis for the total of 208 ISSR and SSR scored as dominant markers (Figure 3) for all three groups, in which the genetic distances varied from 0.13 to 0.61 , but were able to better separate the more distant genotypes. The most similar genotypes were TH030-1 and ID028003-01, and the most dissimilar: Jaran and BB França, Jary Buaya and Butuhan, BB França and ID013004-04, BB França and Jary Buaya, ID017041-01 and BB França, M53 and BB França, and Butuhan and M53. For the G2 cluster in these two dendrograms (Figures 2 and 3), Cacutta 4 is one of the progenitors of the improved diploids, ID028003-01 and TH030-1, which is in agreement as to their genealogy.

In the dendrogram generated by 30 SSR markers, scored as co-dominant markers (Figure 4), the genotypes were separated into 5 groups with distances varying from 0.27 to 0.89. This demonstrates that the SSR markers used as co-dominant markers have a much greater discrimination power (Creste et al., 2003). This dendrogram (Figure 4) separated the genotypes into G1: ID013004-04 and ID017041-01, G2: ID280031, Jaran, Ouro, TH0301 and M53, G3: BB França, Tjau Lagada, Butuhan and Hibrido AB, G4: Calcutta4, Khai Nan On and Jary Buaya, and G5: Lidi.

The most similar genotypes were the improved diploids in G1, ID013004-04 (AA) and ID017041-01 (AA), both susceptible to finger drop. This is in agreement with the fact that they share the same mother and grandmother, Madang, respectively, in their genealogy. The most dissimilar genotypes were Tjau Lagada (BB) and ID013004-04 (AA), 0.89. G2 only separated the genotypes according to their genomic constitution. G3 is represented by both MR and R genotypes to finger drop. G4 only separated the genotypes according to their genomic constitution and Lidi was separated in G5. This separate group for Lidi was expected as also mentioned earlier for the other two dendrograms, due to its unique translocations and inversions being considered a unique genotype (Shepherd, 1999). Thus, the cluster analysis did not show a perfect separation of the genotypes according to finger drop resistance, or genealogy. Similar results were obtained by Creste et al. (2003), whose study based on microsatellite primers did not show a perfect separation between cultivated diploids, wild, and improved hybrids. The authors noted that some genotypes were grouped according to geographical origins, while others had no other relationship.

Amorim et al. (2008) using SSR markers and diploid genotypes, also found no complete separation among improved, cultivated, and wild hybrids, and some diploids were grouped based only in their geographical origin. In this study, there was no separation of genotypes based solely on geographic origin, but genotypes were grouped based on their genomic constitution.

Even though none of the three dendrograms showed perfect separation regarding finger drop resistance/susceptibility, the one generated by SSR markers as co-dominant markers

Genetics and Molecular Research 16 (3): gmr16039554 
better discriminated the genotypes regarding genomic constitution, genealogy, and RFD. This information is important, since these diploids are used in the banana genetic breeding program aiming to develop fruits with RFD.

\section{Nonparametric tests analysis}

Although the Musa spp genome has been recently sequenced (D'Hont et al., 2012), bananas are still considered an orphan crop. Bananas are made up by complex genomic combinations (genomes A and B), are parthenocarpic, and this characteristic alone hinders obtainig representative genetic linkage maps (Shepherd, 1999). Therefore, non-conventional methodologies, such as nonparametric tests, become attractive to overcome the lack of prerequisites for conventional studies, such as obtainment of segregating populations for QTL association studies. Nonparametric tests using the Spearman correlation procedure and Kruskal-Wallis are widely found in the literature (Mace et al., 2006; Mondal and Badigannavar, 2010; Singh et al., 2013).

Mace et al. (2006) used nonparametric tests in 22 groundnut genotypes with differing levels of resistance to rust using 23 SSR markers. The results showed that a total of eight SSR loci were associated with rust resistance through Kruskal-Wallis and AMOVA tests. Their results also demonstrated that the SSR loci identified on the diverse set of 22 genotypes indicate that non-traditional methodologies, such as nonparametric tests, in comparison to traditional ones, such as QTL analysis undertaken on a segregating F2 and RIL populations of 4 ICRIST mapping populations for rust resistance, can be employed to associate genomic regions with traits of importance.

Mondal and Badigannavar (2010) also used nonparametric tests to study association of SSR markers linked to rust and late leaf spot resistance in a set of 20 cultivated groundnut genotypes. Three and four SSR alleles were found associated with rust and late leaf spot resistance, respectively.

Nonparametric tests were also used by Singh et al. (2013) with screening of 24 polymorphic SSRs in 36 cultivated pigeon pea with different levels of resistance to Fusarium wilt. Kruskal-Wallis and simple regression detected significant association of six SSR markers with Fusarium wilt resistance.

Although finger drop may be considered a quantitative characteristic, in our study, nonparametric tests were carried out in order to investigate possible association among 208 ISSR (139) and SSR (69) bands and two variables of resistance to fruit finger drop: v1: force I Newtons $(\mathrm{N})$ necessary to detach the fruit from the pedicel using a mechanical detacher and v2: a scale varying from $1-3$, where $1=$ resistant to finger drop, $2=$ moderately resistant to finger drop, and 3 = susceptible to finger drop, developed by Pereira et al. (2004). The v1 variable varied between $101.2 \mathrm{~N}$ for the most resistant genotype (BB França) to 5.7 for the most susceptible (Lidi).

For the entire analysis, correlation values varied from -0.05803 to 0.79772 , but only higher correlations (above 70\%) were taken into consideration (Table 4). Correlations were only found for the v1 variable, and the highest 12 correlations are presented in Table 4, which varied from -0.71005 to +0.79772 . The highest correlation with the v1 variable was for marker/bands ISSR2B6 and MASR189B3, +0.79772. A positive correlation means that the presence of the band (1) is possibly linked to the v1 variable (Newton force to detach the fruit from the pedicel using a mechanical fruit detacher; Pereira et al., 2004). Seven bands

Genetics and Molecular Research 16 (3): gmr16039554 
presented negative correlation, which means that the absence of the band would identify possible resistant genotypes to finger drop.

Table 4. Nonparametric data, Spearman correlation, Kruskal Wallis test and 2 values for 10 ISSR bands associated with the resistance to finger drop (RFD) variable.

\begin{tabular}{l|c|c|c|c}
\hline Marker/band & Variable (v1) & Spearman (rs) & $\chi^{2}$ & $\operatorname{Pr}>\chi^{2}$ \\
\hline ISSR50B13 & $\mathrm{v} 1$ & $-0.71005^{* *}$ & $5.0417^{*}$ & 0.0247 \\
\hline Ma1/27B1 & $\mathrm{v} 1$ & $-0.71005^{* *}$ & $5.0417^{*}$ & 0.0247 \\
\hline MASR148B1 & $\mathrm{v} 1$ & $-0.71714^{* *}$ & $5.1429^{*}$ & 0.0223 \\
\hline ISSR2B7 & $\mathrm{v} 1$ & $-0.71714^{* *}$ & $5.1429^{*}$ & 0.0233 \\
\hline ISSR50B7 & $\mathrm{v} 1$ & $-0.75056^{* *}$ & $5.6333^{* *}$ & 0.0176 \\
\hline MASR185B1 & $\mathrm{v} 1$ & $-0.75056^{* *}$ & $5.6333^{* *}$ & 0.0176 \\
\hline MASR185B2 & $\mathrm{v} 1$ & $-0.77460^{* *}$ & $6.0000^{* *}$ & 0.0143 \\
\hline ISSR2B8 & $\mathrm{v} 1$ & $+0.67082^{*}$ & $4.5000^{*}$ & 0.0339 \\
\hline ISSR71B3 & $\mathrm{v} 1$ & $+0.69631^{*}$ & $4.3636^{*}$ & 0.0367 \\
\hline ISSR45B2 & $\mathrm{v} 1$ & $+0.75593^{*}$ & $4.0000^{*}$ & 0.0400 \\
\hline ISSR2B6 & $\mathrm{v} 1$ & $+0.79772^{* *}$ & $5.7273^{* *}$ & 0.0167 \\
\hline MASR189B3 & $\mathrm{v} 1$ & $+0.79772^{* *}$ & $5.7273^{* *}$ & 0.0167 \\
\hline
\end{tabular}

$* *$ Significant at $1 \%$ probability. ${ }^{*}$ Significant at $5 \%$ probability. $\left(\chi^{2}\right.$, chi square test $) . v 1=$ force in Newtons to detach fruit from pedicel using a mechanical fruit detacher (Pereira et al., 2004).

Our study shows that markers ISSR50, ISSR2, and SSR: MASR185 are interesting because one single marker yielded 2, 3, and 2 bands possibly linked to finger drop resistance, respectively.

Although nonparametric tests are limited, enabling restricted inferences, these tests were most appropriate to use in our data, since it did not follow normal distribution. In our study, the results were surprisingly positive, since no correlation was expected due to the possible quantitative nature of the finger drop variables. However, our study shows that high (negative and positive) significant correlations were found and may be explored in bananabreeding programs aiming the development of bananas more resistant to finger drop, a major concern among consumers.

Given the presence or absence of the bands and negative and positive correlations, it is possible to select in favor or against the presence of bands and make up a combination of these bands to be used in marker-assisted selection. The ideal is to use a combination of all bands in order to increase the chances of success for use in marker-assisted selection.

Sequencing of these bands will allow the design of sequence characterized amplified region markers. This will be the next step towards the validation of data and possible use in marker-assisted selection for this characteristic. These markers may then be used in combinations in order to best convey results during the validation process. It is worth mentioning that this is the first report of the use of nonparametric tests to study association of markers with finger drop resistance in bananas, and validation of these markers will enable banana genetic breeding programs worldwide to overcome one of the major bottlenecks in the banana-breeding program, which concerns finger drop of the fruit - reducing market value.

\section{ACKNOWLEDGMENTS}

The authors would like to thank Conselho Nacional de Pesquisa e Desenvolvimento $(\mathrm{CNPq})$ for the financial support of the project.

Genetics and Molecular Research 16 (3): gmr16039554 


\section{REFERENCES}

Amorim EP, Reis RV, Santos-Serejo JA, Amorim VBO, et al. (2008). Variabilidade genética estimada entre diplóides de banana por meio de marcadores microssatélites. Pesqui. Agropecu. Bras. 43: 1045-1052. https://doi.org/10.1590/ $\underline{\text { S0100-204X2008000800014 }}$

Amorim EP, Lessa LS, Ledo CAS, Amorim VBO, et al. (2009). Caracterização agronômica e molecular de genótipos diploides melhorados de bananeira. Rev. Bras. Frutic. 31: 154-161. https://doi.org/10.1590/S0100-29452009000100022

Amorim EP, Silva PH, Ferreira CF, Amorim VBO, et al. (2012). New microsatellite markers for bananas (Musa spp). Genet. Mol. Res. 11: 1093-1098. https://doi.org/10.4238/2012.April.27.8

Amorim EP, Amorim VBO, Santos-Serejo JA and Silva SO (2016). O Agronegócio da Banana. 1ed.Brasília. Embrapa 1: 171-200.

Botstein D, White RL, Skolnick M and Davis RW (1980). Construction of a genetic linkage map in man using restriction fragment length polymorphisms. Am. J. Hum. Genet. 32: 314-331.

Cerqueira ARC, Silva O and Medina VM (2000). Avaliação da resistência à queda de frutos de bananeira (Musa spp.) por diferentes métodos. In: Simpósio Brasileiro de Melhoramento de Fruteiras 2, Viçosa. Resumos nos anais do Simposio Brasileiro de Melhoramento, 175.

Cowan AR (1992). Nonparametric Event Study Tests. Rev. Quant. Finance Account. 2: 343-358. https://doi.org/10.1007/ BF00939016

Creste S, Tulman Neto A, Silva SO and Figueira A (2003). Genetic characterization of banana cultivars (Musa spp.) from Brazil using microsatellite markers. Euphytica 132: 259-268. https://doi.org/10.1023/A:1025047421843

Creste S, Benatti T, Orsi MR, Risterucci A-M, et al. (2006). Isolation and characterization of microsatellite loci from a commercial cultivar of Musa acuminata. Mol. Ecol. Notes 6: 303-306. https://doi.org/10.1111/j.1471$\underline{8286.2005 .01209 . \mathrm{x}}$

Crouch HK, Crouch JH, Jarret RL, Cregan PB, et al. (1998). Segregation at microsatellite loci in haploid and diploid gametes of Musa. Crop Sci. 38: 211-217. https://doi.org/10.2135/cropsci1998.0011183X003800010035x

Crouch JH, Crough HK, Tenkouano A and Ortiz R (1999). VNTR- based diversity analysis of 2x and 4x full-sib Musa hybrids. Electron. J. Biotechnol. 2: 99-108. https://doi.org/10.2225/vol2-issue3-fulltext-1

Cruz CD (2006). Programa GENES: aplicativo computacional em genética e estatística. UFV, Viçosa, 442.

D'Hont A, Denoeud F, Aury JM, Baurens FC, et al. (2012). The banana (Musa acuminata) genome and the evolution of monocotyledonous plants. Nature 488: 213-217 https://doi.org/10.1038/nature11241.

Doyle JJ and Doyle JL (1990). Isolation of plant DNA from fresh tissue. Focus 12: 13-15.

FAO - Food and Agriculture Organization (2016). FAO statistical databases. Available at [http://www.faostat.fao.org]. Accessed October 10, 2016.

Grapin A, Noyer JL, Carreel F, Dambier D, et al. (1998). Diploid Musa acuminata genetic diversity assayed with sequencetagged microsatellite sites. Electrophoresis 19: 1374-1380. https://doi.org/10.1002/elps.1150190829

Hicks EW (1934). Finger dropping from bunches of Australian Cavendish Bananas. J. Counc. Sci. Ind. Res. 7: 165-168.

Hippolyte I, Jenny C, Gardes L, Bakry F, et al. (2012). Foundation characteristics of edible Musa triploids revealed from allelic distribution of SSR markers. Ann. Bot. 109: 937-951. https://doi.org/10.1093/aob/mcs010

Imsabai W, Saichol K and Doorn W (2006). Physiological and biochemical changes during banana ripening and finger drop. Postharvest Biol. Technol. 39: 211-216. https://doi.org/10.1016/j.postharvbio.2005.10.001

Iniguez-Luy FL, Voort AV and Osborn TC (2008). Development of a set of public SSR markers derived from genomic sequence of a rapid cycling Brassica oleracea L. genotype. Theor. Appl. Genet. 117: 977-985. https://doi.org/10.1007/ $\underline{\mathrm{s} 00122-008-0837-9}$

Kruskal JB (1964). Multidimensional scaling by optimizing goodness of fit to a nonmetric hypothesis. Psychometrika 29: 1-27. https://doi.org/10.1007/BF02289565

Lagoda PJL (1998) Diploid Musa acuminata genetic diversity assayed with sequence-tagged microsatellite sites. Electrophoresis 19: 1374-1380.

Lamare A and Rao SR (2015). Efficacy of RAPD, ISSR and DAMD markers in assessment of genetic variability and population structure of wild Musa acuminata colla. Physiol. Mol. Biol. Plants 21: 349-358. https://doi.org/10.1007/ s12298-015-0295-1

Lu Y, Zhang X, Pu J, Qi Y, et al. (2011). Molecular assessment of genetic identity and genetic stability in banana cultivars (Musa spp.) from China using ISSR markers. Aust. J. Crop Sci. 5: 25-31.

Mace ES, Phong EDT, Upadhyaya ES, Chandra S, et al. (2006). SSR analysis of cultivated groundnut (Arachis hypogaea L.) germplasm resistant to rust and late leaf spot diseases. Euphytica 152: 317-330. https://doi.org/10.1007/s10681006-9218-0

Genetics and Molecular Research 16 (3): gmr16039554 
Marriott J (1980). Bananas - physiology and biochemistry of storage and ripening for optimum quality. Crit. Rev. Food Sci. Nutr. 13: 41-88. https://doi.org/10.1080/10408398009527284

Mingoti AS (2005). Análise de dados através de métodos de estatística multivariada: uma abordagem aplicada. UFMG, Belo Horizonte, 295.

Mondal S and Badigannavar AM (2010). Molecular diversity and association of SSR markers to rust and late leaf spot resistance in cultivated groundnut (Arachis hypogaea L.). Plant Breed. 129: 68-71. https://doi.org/10.1111/j.14390523.2009.01635.x

Nei M and Li W-H (1979). Mathematical model for studying genetic variation in terms of restriction endonucleases. Proc. Natl. Acad. Sci. USA 76: 5269-5273. https://doi.org/10.1073/pnas.76.10.5269

Pereira MCT, Salomão LCC, Silva SO, Cecon PR, et al. (2004). Suscetibilidade à queda natural e caracterização dos frutos de diversos genótipos de bananeiras. Rev. Bras. Frutic. 26: 499-502. https://doi.org/10.1590/S010029452004000300030

Putra ETS, Zakaria W, Abdullah NAP and Saleh G (2010). Weak neck of Musa sp. cv. 'Rastali': a review on its genetics, crop nutrition, and postharvest. J. Agron. 2: 45-51.

Racharak P and Eiadthong W (2007). Genetic relationship among subspecies of Musa acuminate Colla and A-genome consisting edible cultivated bananas assayed with ISSR markers. Songklanakarin J. Sci. Technol. 29: 1479-1489.

Salazar BM and Serrano EP (2013). Etiology and Postharvest Control of Finger Drop Disorder in 'Cuarenta Dias' Banana (Musa acuminata AA Group). Philipp. Agric. Sci. 96: 163-171.

SAS Institute Inc. (2002-2004). Cary, NC: SAS Institute Inc.

Shepherd K (1999). Cytogenetics of the genus Musa. International Network for the Improvement of Banana and Plantain, Montpellier, France.

Silva PRO, Jesus ON, Creste S, Figueira A, et al. (2015). Evaluation of microsatellite loci from libraries derived from the wild diploid 'Calcutta 4' and 'Ouro'banana cultivars. Genet. Mol. Res. 14: 11410-11428. https://doi.org/10.4238/2015. September.25.9

Simmonds NW and Shepherd K (1955). The taxonomy and origins of the cultivated bananas. The journal of the Linean Society of London, London, 55: 302-312.

Singh AK, Rai VP, Chand R, Singh RP, et al. (2013). Genetic diversity studies and identification of SSR markers associated with Fusarium wilt (Fusarium udum) resistance in cultivated pigeonpea (Cajanus cajan). J. Genet. 92: 273-280. https://doi.org/10.1007/s12041-013-0266-7

Sokal RR and Rohlf FJ (1962). The comparison of dendrograms by objective methods. Taxon 11: 33-40. https://doi. org $/ 10.2307 / 1217208$

Statistica for Windows (2002). Computer program manual. Version 6. Tulsa: Statsoft, 1CD-ROM.

Vaz Patto MC, Satovic Z, Pêgo S and Fevereiro P (2004). Assessing the genetic diversity of Portuguese maize germplasm using microsatellite markers. Euphytica 137: 63-72. https://doi.org/10.1023/B:EUPH.0000040503.48448.97

Whitley E and Ball J (2002). Statistics review 6: Nonparametric methods. Crit. Care 6: 509-513. https://doi.org/10.1186/ $\underline{\mathrm{cc} 1820}$

Genetics and Molecular Research 16 (3): gmr16039554 